\title{
Social Dynamics of Field Archaeology in Parts of Nigeria
}

\author{
Samuel Oluwole Ogundele \\ Department of Archaeology and Anthropology, University of Ibadan, Ibadan, Oyo State, Nigeria \\ E-mail: oluwoleogundele@yahoo.com
}

KEYWORDS Tivland; Ungwailand; Nigeria; local leaders; oral traditions; field archaeology

\begin{abstract}
This paper addresses some of the conceptual and methodological issues centring on archaeological practice in Africa, using the Tiv and Ungwai peoples of central Nigeria as our reference point. Research efforts todate, show in a fascinating manner that archaeologists can raise the level of intelligibility of the material remains at their disposal if models rooted in humanistic subjects such as oral tradition and ethnography are carefully applied. Similarly, subjectivity, which blurs the true picture of the past of man, can be reduced to the barest minimum when we are able to obtain a new understanding and appreciation of the centrality of the local people to archaeological field operations. Suffice it to say that the local people of a given study area are the custodians or descendants of the custodians of the set of heritage resources the archaeologist is investigating. Therefore, by tempering rugged technical expertise (involving an array of surveying methods and excavations among other things) with a new spirit of collaboration with the local Tiv and Ungwai, we were able to produce some archaeological knowledge devoid of imaginary tendencies.
\end{abstract}

\section{INTRODUCTION}

Studies have been carried out among the Tiv and Ungwai - two of the major savanna peoples of Nigeria. These peoples are located in Benue and Niger States respectively (see Fig. 1). They are predominantly subsistence farmers growing such crops as guinea corn, a variety of yams, cassava and different leaf greens. Other occupations of these peoples include wood carving, pottery making, basketry, weaving, dyeing and blacksmithing. In order to deepen our understanding of aspects of the lifeways of these two ethnic groups, several archaeological methods and approaches were employed (Ogundele, 1995; 2004; Gamble, 2001; Afigbo, 2002; 11 - 25; Fagan, 1997). Archaeological science is a multi-facetted discipline and by this token, the practitioner is supposed to know how to borrow models critically from some related fields such as Sociology, Anthropology, History, Botany and Zoology. In addition, he must know when and where to apply such models so as to pave the way for optimum production of archaeological knowledge. The heart of all these efforts is the collection, analysis and interpretation as well as transmission of historical and cultural information in specific social contexts and at different time-periods. But despite this, the philosophy of teamwork for proper archaeological operations must be given pride of place. The full implications of the multi-facettedness of archaeology with particular reference to fieldwork are hardly appreciated and understood by a lot of people including even the practitioners of the profession (Ogundele, 2004; Orser and Fagan, 1995; Robertshaw, 1990). This position is a reflection of poor conceptualization of the subject. Thus, for example, archaeology is defined by some scholars as a body of scientific techniques for retrieving material remains of the behaviour of a past population. This means that an archaeologist is atechnician who handles such items of equipment as quick-sets, compasses, tapes and alidades in the field in order to survey or sample a given site. The bottom line is the getting of glimpses of the past. For making sense of the data obtained from the field, he starts analyzing the material in the laboratory. This is later followed by interpretation.

Given this conceptual and methodological framework, student archaeologists are basically exposed to the technical aspect of archaeological training. That is, knowing how to survey a site, grid it and carry out excavations. At the analytical level, he employs a lot of rigorous quantitative techniques for reducing subjectivity to the barest minimum (Collingwood, 1946; Orser and Fagan, 1995). Many an archaeologist however hardly appreciates the fact that at the level of collection of data, he has a lot of epistemological and methodological problems which cannot be resolved only by applying models rooted in scientific and technological fields. This lack of awareness creates a lot of gaps in our knowledge of the past. We need to realize that an archaeological site is the property of a given community. That is, the members of a given host community who are the 


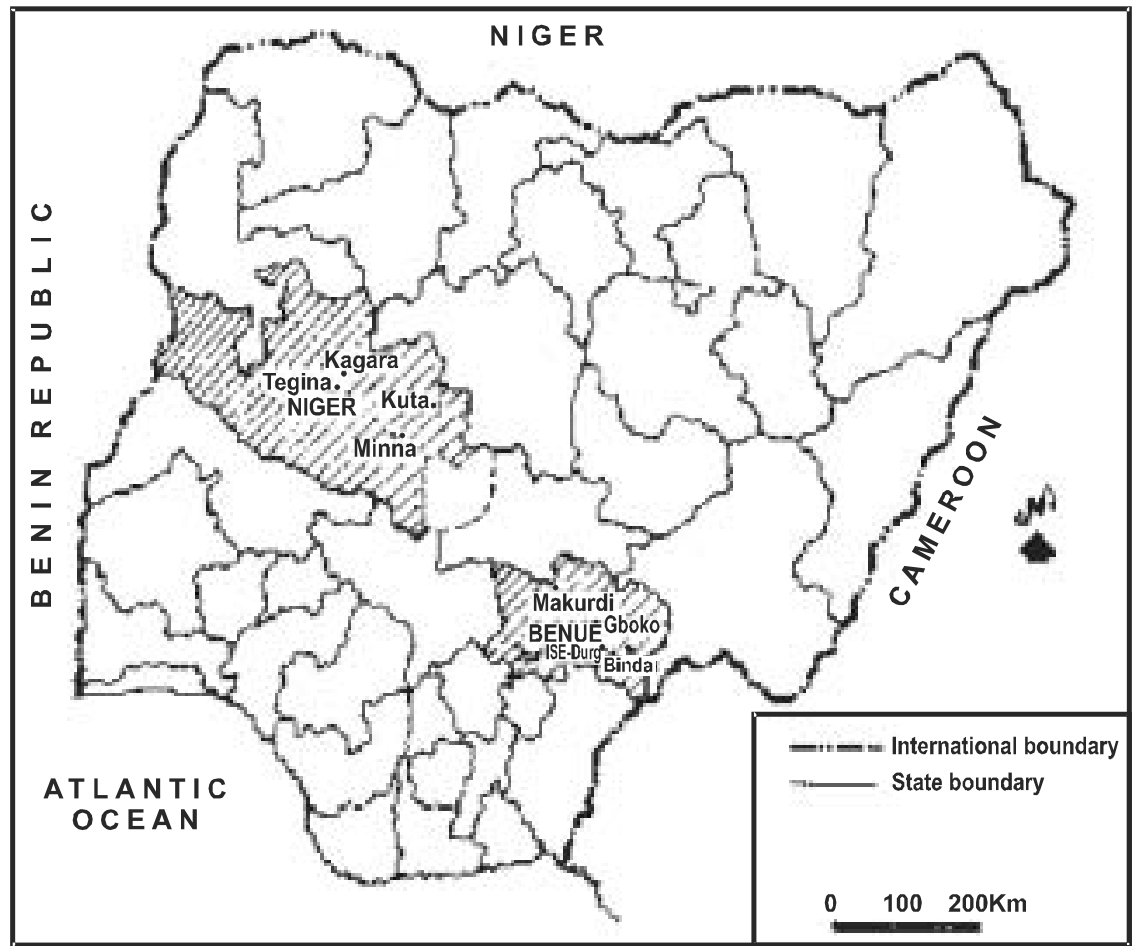

Fig. 1. Map of Nigeria showing the general research area

custodians of the cultural resources can speak much better about what they represent in terms of the meanings and world-views of the authors and/or their descendants if the team of archaeologists is able to appreciate the central role of the local people. This is achievable through the formulation and critical application of models enshrined in humanistic subjects like Sociology and History (DeCorse, 1996; Hall, 1996).

\section{THE TIV EXPERIENCE}

Research activities among the Tiv have shown that archaeological fieldwork can be an extremely rewarding and refreshing exercise if the operators are able to design and execute it within a systemic frame of reference.

Archaeological fieldwork is a big package, which embraces technical know-how and social dynamics. The inability or unwillingness of many archaeologists to appreciate and respect the second dimension of field archaeology subtly or otherwise delays the rapid growth of the discipline. One major aim of the research in Tiv land was to critically examine aspects of Tiv culture and settlement patterns from a diachronic as well as synchronic perspective. The success of the fieldwork was hinged on our ability to carry a lot of the present-day Tiv along with us. The local people were to be seen and related to as partners in progress. The relevant government officials in the Benue State Centre for Arts and Culture made contacts with the grassroots people. This was a necessary background exercise to hard archaeological operations.

Our local informants were able to convince the settlers of the dispersed compounds dotting the landscapes that what we were aiming at was the promotion of Tiv cultural adaptations and history, not to impose any tax on them. The local people therefore became very hospitable to us during the exercise. Indeed, a lot of fruits such as oranges and mangoes were always kept for us before arriving in any compound for work by the local people. Similarly, yams were either roasted or cooked for us everyday before returning to our camp. On several occasions, pounded yam the favourite food of the Tiv was served usually with okra soup. This development destroyed suspicions, thereby creating an enabling 
environment for research. Our experience here dispels the old myth that the Tiv are a hostile and violent people (Ogundele, 1995).

In the course of this research, members of the team began to know more about human cultures - the variations and the common features (reflecting our common humanity) and the corresponding need to respect such phenomena. Thus for example, the Tiv people usually feel unhappy whenever an outsider rejects food being offered. They assume that such rejection means snubbing them. In their world-view, a snub cannot love. Consequently, the Tiv will be suspicious of the good intentions of that visitor or a group of visitors. This kind of negative relationship leads to poor archaeological knowledge production. Indeed, much cannot be gained by the field researcher who is working with the grassroots people who are already biased against him. Whenever we were not ready to eat their food, we normally tried to explain through our informants with broad smiles. This is one strategy of reassuring them of our friendliness and good intentions at all times. In this respect, the ability to speak and understand some of the key words of Tiv language has always been very profitable. The local people do necessarily have a lot of information to furnish about a given archaeo-logical site, which forms a part of their cultural landscape. Such information will go a long way in helping the archaeologist to know how to handle the site. The soundness of models to be used for investigating a site depends to a large extent on the input of the local people, who are the custodians of these cultural resources or heritage.

Further work in the Binda locality approximately 40 kilometres south-south east of Adikpo, which was the first port of call (Adikpo), brought us closer to the rural Tiv. Here we are living directly with the people in one of the compounds. The situation was an added advantage for having some greater insights into the cultural values of the Tiv. For example, we became more interested in Tiv food especially pounded yam, while they (the Tiv) too started to enjoy beans cooked by us. This mutuality encouraged greater cooperation, which eventually led to the discovery of new archaeological sites like Kpe and Bako. Kpe and Bako hilltop settlements which were occupied during the pre-colonial times by the Tiv were mentioned to us in the course of doing ethnographic research in the region.

The second field season in the Binda locality coincided with the period of farm preparation. This is usually between February and early March. This is normally a busy time for every Tiv adult, understandably because farming is the main occupation of the people. But despite their tight schedule, they still gave me sufficient attention.

This was done within a cooperative frame of reference. My assistants would wake up very early (at 6 a.m.) to go to their farms. They would then return about 8 a.m. in readiness for our own archaeological work on top of the hill settlement. To our greatest surprise these field assistants would still work with us up to 3 p.m. (in the evening). A lot of roasted yams were usually consumed during the break time each day. Some of the members of the archaeological team attended a church service on one of the Sundays. This was one of the efforts made to foster a sense of friendliness and appreciation of the world-view of the local Tiv. Many farmers brought some portions of their seed yams and rice as well as cutlasses and hoes to the church. Special prayers were offered to these crops and implements. These crops would be mixed up with the remaining ones (crops) at home for planting later in their farms. Such blessings from God would lead to some bumper harvests. This applied only to the Christians who are of course in the majority in the study area.

Many present-day compounds were mapped and investigated during this fieldwork. Indeed, we were allowed to enter their huts and we studied the ways material items like storage pots, beds, hoes, cutlasses and calabashes were arranged. Such knowledge would be helpful for having some glimpses of how space was used in the archaeological past, since the present-day Tiv were the descendants of the settlers of the archaeological sites being investigated. The two huts of the archaeologists were continuously filled up by the Tiv boys and even some elderly ones who were very interested in the on-going research. There was hardly a day without a piece of information from the local Tiv concerning new archaeological sites within their locality. It became very clear during the research that the application of models enshrined in social anthropology was most indispensable if the archaeologist must collect data that are highly intelligible. The local people need to play some central roles. Every night was like a cultural festival time, because the people of Tse-Gbashanam compound and occasionally friends from Akuyi and Wombo 
would entertain us with their famous traditional dance and music called "Kwagh-hir" .

\section{THE UNGWAI EXPERIENCE}

In order to get optimum archaeological heritage knowledge, our team embarked on a public enlightenment campaign. That is meeting most of the very important local leaders and compound heads and informing them through one or two of the educated Ungwai people about archaeological work and its importance to the region. This proved a successful strategy for field archaeology in the region. However, one must appreciate the fact that this method of approach demands a great deal of planning with respect to such indices as time, energy and money. The high degree of profitability of this public enlightenment campaign at least in this study area makes the approach a positive development in modern archaeological enterprise. The bottom line of all these efforts is that archaeologists must adopt an open method which paves the way for socially engaged and engaging archaeological operations (Ogundele, 1995; Izumi and Motaki, 1995). In this particular case, the museums division of the Niger State centre for Arts and Culture were fully involved. For example, all cultural officers including the archaeologists in this division had one role or the other to play, concerning the field archaeological research in Ungwailand. It was therefore very easy for these officials to carry the message to the local chiefs and the Emir of Kagara. Kagara is the capital of Ungwailand. As a result of this fore knowledge, the local leaders were extremely glad when we finally visited them, just before the commencement of the hard archaeological work. The Emir of Kagara (the paramount ruler of the region) was particularly delighted about our project because it would expose the area to a lot of tourist opportunities. These opportunities are capable of transforming the social and economic life of the Ungwai community. This mutual under-standing also led to the provision of free accommodation for the visiting archaeologists and assistants that joined the team from Minna, the capital town of Niger State of Nigeria. The Ungwai experience shows that archaeological fieldwork and/or archaeological heritage management should be conceptualized within the framework of collectivity - orientation in order to reduce to the barest minimum the great amount of unknow- ability normally associated with past lifeways of people.

At a special meeting of the local chiefs, top officials of the Rafi local government council (the local government area within which work was to be done) and the archaeologists, it was decided that the grassroots leaders be informed about our mission in their territory. This is one way of reducing suspicions, frictions and the likes to the barest minimum. The Emir (the paramount leader) instructed his assistants to inform the various village heads of the socio-economic benefits derivable from such an archaeological project. Such benefits include job opportunities for some members of the community in the future when a community museum is established, and the provision of social amenities like pipe-borne water and electricity by the state and/or federal government(s), to encourage tourists to come to the community. The local people therefore became very aware of the numerous advantages of tourism industry, which is a powerful agent of socioeconomic change. With all these assurances, the stage was set for participatory field archaeology. That is, an archaeological research capable of bringing the past as close to life as possible. This is because the people who own the culture feature prominently in the spheres of collection, analysis and interpretation of archaeological remains. Similarly, it is a kind of archaeology that brings joy and hopes to the custodians of the heritage resources being studied (Hodder, 1982; Johnsen and Olsen, 1992).

A lot of young boys and middle-aged men were anxious to work with us. They furnished a great deal of information about aspects of the settlement history of the Ungwai. The elderly ones also proved to be a great asset since they were able to tell us part of what they had learned from their parents concerning how, when and where the Ungwai settled on entering the Kaduna river valley in the remote past. For example, oral traditions have it that the Ungwai are made up of four clans that eventually settled on four of the major hill complexes within the valley. These clans are as follows: Kabitu, Karaya, Karaku and Makangara. Their choice of these hilltops for settlement purposes was hinged on securityconsciousness. The Ungwai migrated from Niger Republic to their present location in Nigeria during the pre-colonial times. Available oral traditional search to-date reveals that the present location was favoured by the Ungwai because of fertile 
soils for agricultural purposes and local hill ranges that served as a defensive mechanism. The original name of this ethnic group was Zabriama before they later changed to Ungwai. This new name was given to them by the Hausa people who were one of their neighbours.

An enormous corpus of data about aspects of the Ungwai culture and settlement history was got as a result of the full involvement of the local people in the research. Our reconnaissance efforts became a profitable experience largely because we allowed the guides and other local research assistants to have an input. For example, they (the local assistants) were able to inform us that the depressions identified on the Kabitu hilltop were places from where some earth was removed for construction purposes. Similarly, the small-sized circular structures (mainly the remains of foundations) were said to have represented goat houses. These structures are similar in techniques of construction and size to the ones located in the ethnographic settlements in the surrounding plains (Hodder, 1982; Ogundele, 1995).

\section{CONCLUSION}

Experience among the Tiv and Ungwai peoples of central Nigeria shows that field archaeological operations (if properly conceptualized) are an important tool for human resources development as well as archaeological reconstructions that are as close to life as possible. This kind of conceptualization takes into cognisance the centrality of the local people among whom a research is going to be carried out. This is with a view to allowing them to tell us what they know about their environmental and cultural resources. Such an approach underscores the fact that an outsider no matter his wealth of experience in archaeological heritage management cannot understand very clearly the fundamentals of other people's culture. The authors of the culture being investigated must serve as the pathfinders, otherwise archaeologists would only be busy distorting the facts of history. However, contextualising archaeology from this standpoint, does not mean that the technical integrity of the research should be thrown into the dustbin. Indeed, contextualisation of archaeology cannot be a substitute for high technical integrity rather, both of them must go together. Archaeological fieldwork becomes a rewarding and exciting experience whenever it is done within a systemic frame of reference. Conceiving and evaluating archaeology in this manner should also embrace a consideration of how the custodians of those cultural resources can benefit materially and spiritually from a given research exercise. In other words, doing field archaeology in a community ought to be a give-and-take affair. This is the basis of doing archaeology that is capable of fostering a sense of understanding between a given local community and the archaeologists. As a matter of fact, our archaeological fieldwork among the Tiv and Ungwai of Nigeria was guided by this philosophy.

\section{REFERENCES}

Afigbo, A.E. 2002. "Oral Tradition and the Political Process in Pre-colonial Nigeria." Nigerian Heritage, 11: $11-25$.

Collingwood, R.G. 1946. The Idea of History. London: Clarendon Press.

DeCorse, C.R. 1996. "Documents, Oral Histories and the Material Record: Historical Archaeology in West Africa." World Archaeological Bulletin, 7: 40 - 47.

Fagan, B. 1997. In the Beginning. Boston: Little Brown and Company.

Gamble, C. 2001. Archaeology: The Basics. London: Routledge.

Hall, M. 1996. Archaeology Africa. London: James Currey; Cape Town: David Philip.

Hodder, I. 1982. The Present Past. London: B.T. Batsford.

Izumi, N. and O. Motaki. 1995. Sadakita KofunExcavation of a $7^{\text {th }}$ Century Burial Mound in Okayama Perfecture. Japan: Okayama University.

Johnsen, H. and B. Olsen 1992. "Hermeneutics and Archaeology: On the Philosophy of Contextual Archaeology." American Antiquity, 57(3): 50.

Ogundele, S.O. 1995. "Archaeology and Politics in Africa - A Cautionary Tale." West African Journal of Archaeology, 25: 128-138.

Ogundele, S.O. 2004. Rethinking West African Archaeology. Ibadan: John Archers (Publishers) Ltd.

Orser, C.E. and B.M. Fagan. 1995. Historical Archaeology. New York: Harper Collins College Publishers.

Robertshaw, P. 1990. A History of African Archaeology. London: Heinemann. 